\title{
A large palmar lipoma arising from flexor tenosynovium of the hand causing digital nerve compression: A case report
}

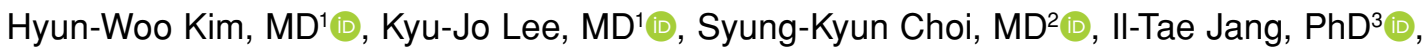 \\ Hyun-Jin Lee, MD ${ }^{1}$ \\ ${ }^{1}$ Nanoori 2bko R\&D Institute, Nanoori Hospital Suwon, Suwon, Republic of Korea \\ ${ }^{2}$ Department of Orthopedic Surgery, Nanoori Hospital Gangnam, Seoul, Republic of Korea \\ ${ }^{3}$ Department of Neurosurgery, Nanoori Hospital Gangnam, Seoul, Republic of Korea
}

Lipoma is a common benign soft tissue tumor. ${ }^{[1]}$ Lipomas are classified according to the anatomic site of the fat cells as dermal, subcutaneous, and subfascial lipomas; or tumors directly related to the muscle, bone, synovium, or nerve. ${ }^{[2]}$ There is a limited number of case reports of lipoma occurring in the hand ${ }^{[3]}$ and most of lipomas occurring in the hand grow very slowly and are asymptomatic. However, depending on their location, lipomas can cause neurological symptoms and tenderness. ${ }^{[4]}$ In the literature, rare cases of lipoma-induced peripheral nerve compression (such as carpal tunnel syndrome) have been reported. ${ }^{[5,6]}$

Herein, we report a case of a large palmar lipoma arising from the flexor tenosynovium of the

Received: May 21, 2020

Accepted: August 27, 2020

Published online: January 06, 2021

Correspondence: Hyun-Jin Lee, MD. Nanoori 2bko R\&D Institute, Nanoori Hospital Suwon, 295, Jungbu-daero, Yeongtong-gu,

Gyeonggi-Do, Republic of Korea.

E-mail: 0083ackmong@naver.com

Doi: $10.5606 /$ ehc. 2021.75678

Citation: Kim HW, Lee KJ, Choi SK, Jang IIT, Lee HJ. A large palmar lipoma arising from flexor tenosynovium of the hand causing digital nerve compression: A case report. Jt Dis Relat Surg 2021;32(1):230-233

\section{(C2021 All right reserved by the Turkish Joint Diseases Foundation}

This is an open access article under the terms of the Creative Commons Attribution-NonCommercial License, which permits use, distribution and reproduction in any medium, provided the original work is properly cited and is not used for commercial purposes (http://creativecommons.org/licenses/by-nc/4.0/)

\section{ABSTRACT}

Lipoma is a common benign soft tissue tumor which rarely occurs in the hand. Lipomas of the hand seldomly cause pain or other symptoms. However, in certain areas, the mass effect from the lipoma may cause clinical symptoms. It rarely involves the deep areas such as synovial membrane and muscle and, sometimes, pressure on the peripheral nerves can cause pain and neurological symptoms. The treatment is surgical resection with a low rate of recurrence. However, the rate of recurrence is high in deep and infiltrating lipomas which preclude complete resection. In this article, we report a case of a large palmar lipoma arising from the flexor tenosynovium of the hand causing digital nerve compression.

Keywords: Digital nerve compression, hand, lipoma, tenosynovium.

hand causing digital nerve compression which was successfully treated with surgery.

\section{CASE REPORT}

A 67-year-old female patient was admitted to our hospital with dullness and tingling in the left hand, and had a large mass in the palmar aspect of the left second and third fingers. The patient previously noticed the mass which was gradually increased in size six months prior to admission. Her medical history was non-specific without any history of trauma or infection. The patient experienced discomfort, when she used her left hand to hold objects. Physical examination revealed a tender soft tissue mass of about $3.0 \times 4.0 \mathrm{~cm}$ in size in the left hand which was relatively fixed to the surrounding area. The mass was positive for the Tinel's sign (Figure 1). A plain radiograph showed soft tissue hypertrophy between the first and second metacarpal bone and between the 
second and third metacarpal bone of the hand. The soft tissue hypertrophy was distinguishable from the surrounding soft tissue by an oval shade reduction (Figure 2). Using magnetic resonance imaging (MRI), we observed a growing intramuscular fatty mass measuring $5.0 \times 3.0 \times 3.7 \mathrm{~cm}$ in size, wrapping around the second flexor tendon, which was located between the flexor pollicis longus and third flexor tendon. The mass did not show an extension into the bone, but showed the same signal intensity as the lipoma in the contrast-enhanced T1 image with a low signal intensity in the $\mathrm{T} 2$ fat suppression image. The contrastenhanced image was typical of an encapsulated subfascial lipoma, which usually does not show contrast enhancement (Figure 3).

The patient underwent mass removal using brachial plexus block. The mass was located between the flexor pollicis longus and the third flexor tendon. We confirmed that the mass was adhered to the second flexor tenosynovium. The tendon proper and the second metacarpal bone were not directly involved. As we observed the digital nerves of the second and third fingers passing over the mass, the entire mass excision was performed by releasing the nerves. The gross examination showed that the mass was yellowish, fatty, well-capsulated, and measured as $3.5 \times 2.5 \times 4.0 \mathrm{~cm}$ in size (Figure 4 ). On histological examination, the mass was composed of mature fat without structural or cellular atypia, contained no necrosis or bleeding, and was surrounded by the synovial lining. The histological diagnosis was reported as a lipoma arising from the tenosynovium (Figure 5). The patient's pain and tingling in her second and third fingers were completely relieved

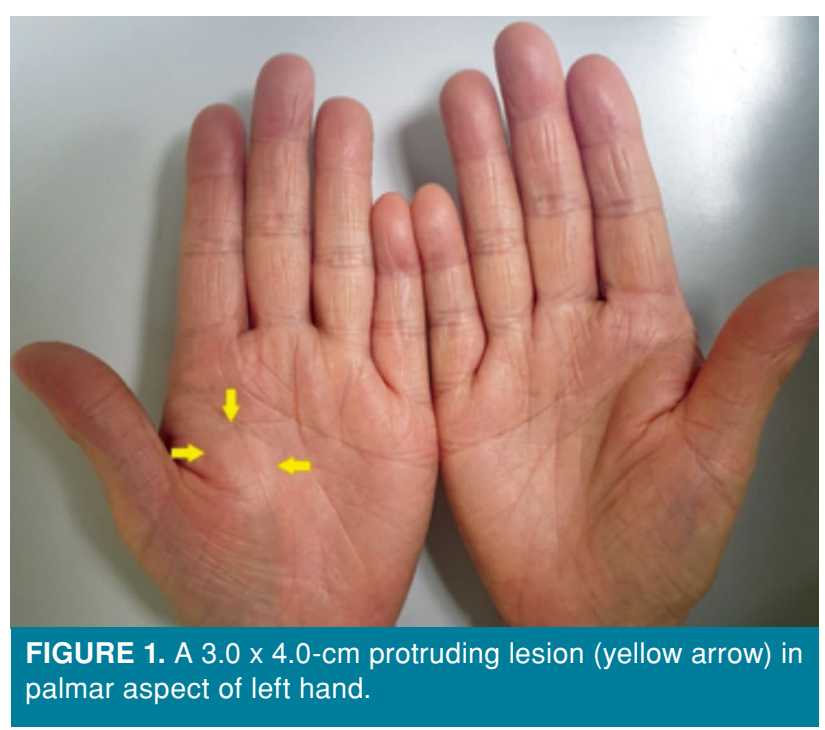

by surgery, and she remained complaint-free at one year of follow-up. A written informed consent was obtained from the patient.

\section{DISCUSSION}

Lipomas of the hands usually form in the subcutaneous layer of the hands. When lipomas occur in the submuscular layer, they typically occur under the thenar muscles and can also appear in the deep structures of the palms, such as the carpal canal or Guyon's canal..$^{[7]}$ Deep palmar lipomas can be difficult to detect and correctly diagnose, as they are located under the palmar fascia and are not easily palpable.

Although there are numerous case reports of lipomas of the tendon sheath occurring in association with tendons in the lower extremity, the number of cases located in the hand is scarce in the literature. ${ }^{[8]}$ There are two types of tendon sheath lipomas: discrete solid masses of adipose tissue (as in our case) and adipose tissue coupled with hypertrophic synovial villi (or lipoma arborescens). ${ }^{[9]}$ Lipomas of the tendon sheath was first described by Bryan et al. ${ }^{[10]}$ and 30 lipoma cases which occurred in the hand were included in the review between 1922 and 1956. ${ }^{[10]}$ Recent reports of lipomas originating from the flexor tendon sheath or tenosynovium are very rare and

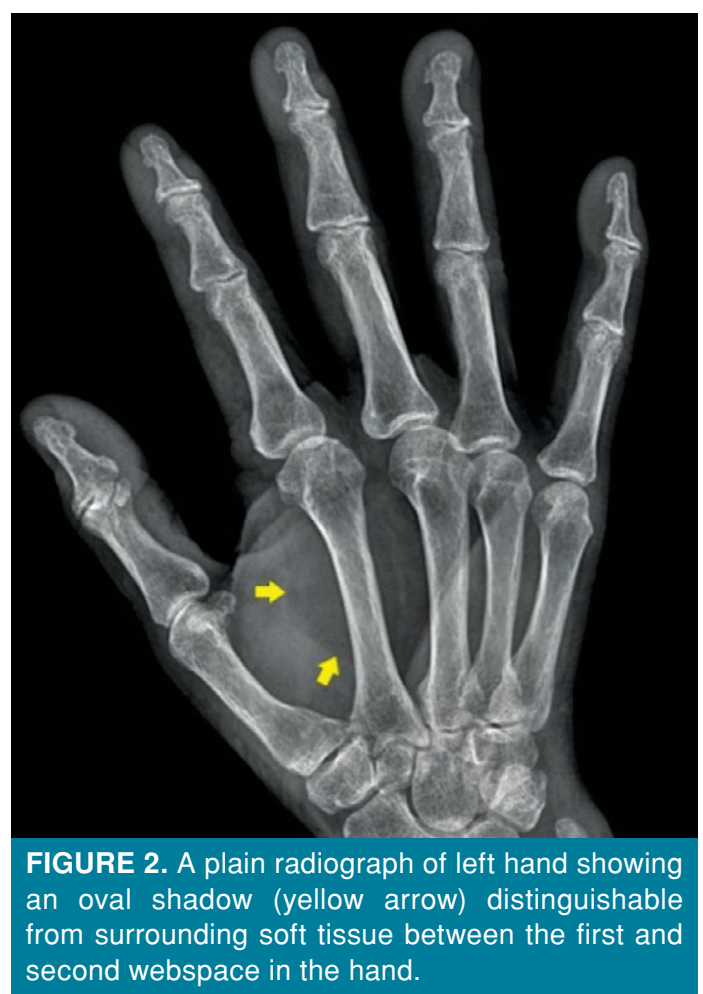



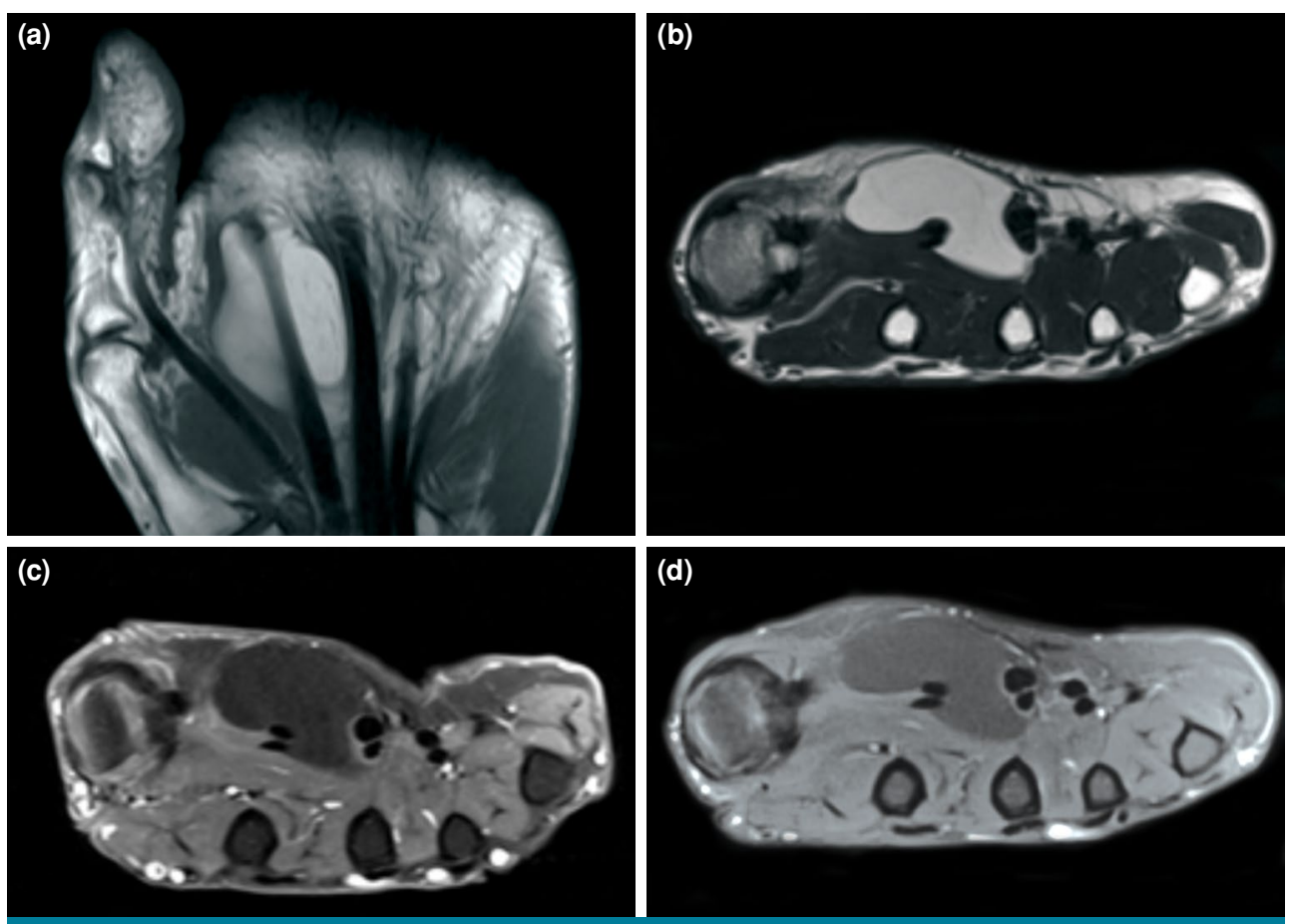

FIGURE 3. (a) A $5.0 \times 3.0 \times 3.7-\mathrm{cm}$ intramuscular fatty mass wrapping around the second flexor tendon in thenar area between flexor pollicis longus and third flexor tendon on magnetic resonance imaging. (b) A contrast-enhanced T1 image showing the same signal intensity as the lipoma. There was no bone extension. (c) A T2 fat suppression image showing low signal intensity. (d) A contrast-enhanced image showing typical findings of an encapsulated lipoma.

usually lead to carpal tunnel syndrome $\mathrm{e}^{[11-14]}$ and rarely affect the wrist. ${ }^{[1]}$ Cases of intramuscular lipoma of tenosynovial origin occurring distal to carpal tunnel are extremely rare.
In cases of a subfascial lipoma, a simple radiographic examination usually shows an oval or circular-shaped mass with reduced shadow. Of note, MRI is the most useful diagnostic imaging
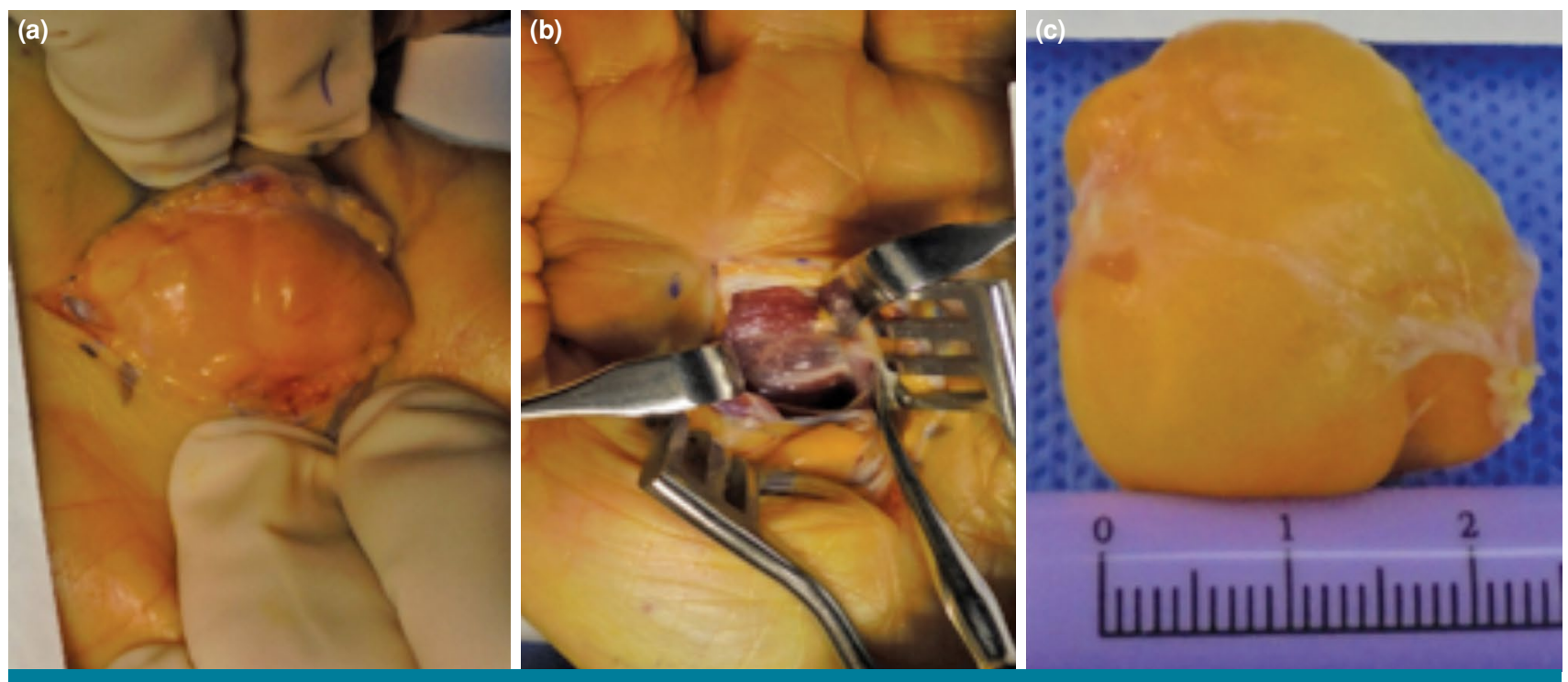

FIGURE 4. (a) In the surgical field, a yellow soft mass was identified between flexor pollicis longus and the third flexor tendon. (b) Mass excision was performed by releasing nerves. (c) The extracted mass was yellowish, fatty, well-capsulated, and measured $3.5 \times 2.5 \times 4.0 \mathrm{~cm}$ in size. 


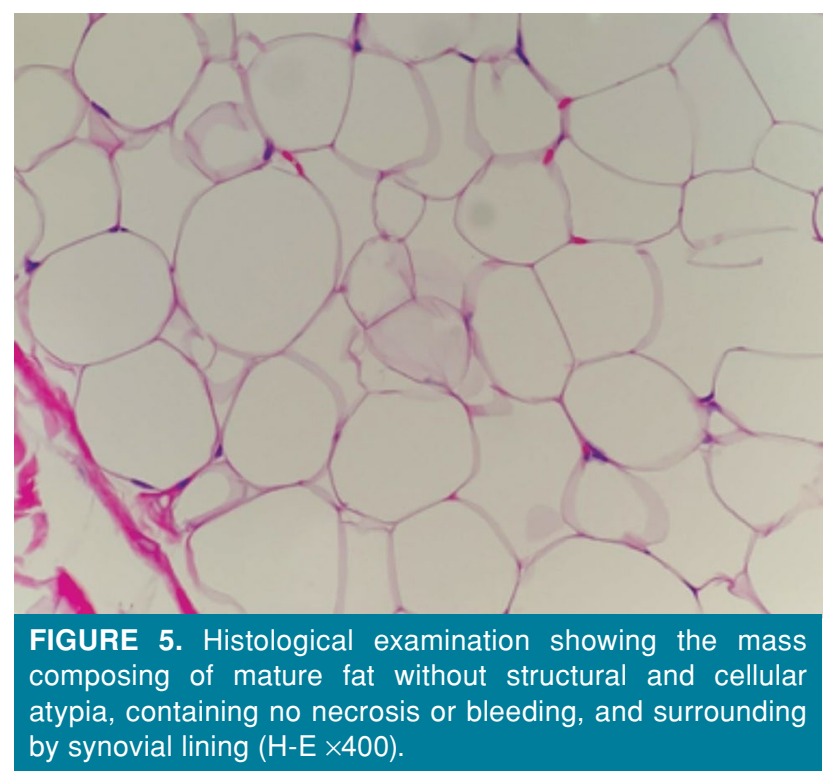

tool in such cases. Capelastegui et al. ${ }^{[15]}$ found that, in 134 cases, MRI demonstrated the cause of the palpable mass with $94 \%$ diagnostic accuracy. Contrast-enhanced T1 images usually show high signals, while contrast-enhanced T2 images show a moderate-to-high signals at the same intensity as the subcutaneous fat layer. Furthermore, understanding the positional relationship between lipomas and their surrounding tissues is useful in establishing a surgical treatment plan.

There is a limited number of reports of malignant transformation of lipomas in the literature. ${ }^{[1]}$ However, if such cases are accompanied by certain neurological symptoms such as discomfort in the hand, histological confirmation and relief of symptoms through surgical removal are necessary. The frequency of recurrence is reported to be about $5 \%$. However, the frequency of recurrence in deep and infiltrating lipomas is high, often due to incomplete tumor resection to preserve the surrounding neurovascular and muscular tissue. ${ }^{[16]}$

In conclusion, although rare, palmar lipoma causing nerve compression can be successfully treated with surgery.

\section{Acknowledgements}

We would like to acknowledge Kyeong-Rae Kim, a Nanoori Scientific Team member, for his valuable assistance in acquiring the full text articles for the literature review and managing digital works.

\section{Declaration of conflicting interests}

The authors declared no conflicts of interest with respect to the authorship and/or publication of this article.

\section{Funding}

The authors received no financial support for the research and/or authorship of this article.

\section{REFERENCES}

1. Nadar MM, Bartoli CR, Kasdan ML. Lipomas of the hand: a review and 13 patient case series. Eplasty 2010;10:e66.

2. Al-Qattan MM, Al-Lazzam AM, Al Thunayan A, Al Namlah A, Mahmoud S, Hashem F, et al. Classification of benign fatty tumours of the upper limb. Hand Surg 2005;10:43-59.

3. Berlund P, Kalamaras M. A case report of trigger wrist associated with carpal tunnel syndrome caused by an intramuscular lipoma. Hand Surg 2014;19:237-9.

4. Fazilleau F, Williams T, Richou J, Sauleau V, Le Nen D. Median nerve compression in carpal tunnel caused by a giant lipoma. Case Rep Orthop 2014;2014:654934.

5. Azwa N, Shalimar A, Jamari S. A Palmar Lipoma with Median and Ulnar Nerve Compressive Symptoms. Malaysian Orthopaedic Journal 2007;1:33-5.

6. Sbai MA, Benzarti S, Msek H, Boussen M, Khorbi A. Carpal tunnel syndrome caused by lipoma: a case report. Pan Afr Med J 2015;22:51.

7. Grivas TB, Psarakis SA, Kaspiris A, Liapi G. Giant lipoma of the thenar--case study and contemporary approach to its aetiopathogenicity. Hand (N Y) 2009;4:173-6.

8. Atik OŞ. What are the expectations of an editor from a scientific article? Jt Dis Relat Surg 2020;31:597-8.

9. Gurich RW Jr, Pappas ND. Lipoma of the Tendon Sheath in the Fourth Extensor Compartment of the Hand. Am J Orthop (Belle Mead NJ) 2015;44:561-2.

10. Bryan RS, Dahlin DC, Sullivan CR. Lipoma of the tendon sheath. J Bone Joint Surg [Am] 1956;38-A:1275-80.

11. Sonoda H, Takasita M, Taira H, Higashi T, Tsumura H. Carpal tunnel syndrome and trigger wrist caused by a lipoma arising from flexor tenosynovium: a case report. J Hand Surg Am 2002;27:1056-8.

12. Vekris MD, Lykissas MG, Beris AE. Median nerve compression secondary to lipoma arising from flexor tenosynovium: a case report. Hand Surg 2007;12:83-6.

13. Kremchek TE, Kremchek EJ. Carpal tunnel syndrome caused by flexor tendon sheath lipoma. Orthop Rev 1988;17:1083-5.

14. Inglis AE, Straub LR, Williams CS. Median nerve neuropathy at the wrist. Clin Orthop Relat Res 1972;83:48-54.

15. Capelastegui A, Astigarraga E, Fernandez-Canton G, Saralegui I, Larena JA, Merino A. Masses and pseudomasses of the hand and wrist: MR findings in 134 cases. Skeletal Radiol 1999;28:498-507.

16. Murphey MD, Carroll JF, Flemming DJ, Pope TL, Gannon FH, Kransdorf MJ. From the archives of the AFIP: benign musculoskeletal lipomatous lesions. Radiographics 2004;24:1433-66. 